\title{
Aging effect on transformation characteristics and tensile properties of a Ti-Ni-Co alloy
}

\author{
Y. Kishi, Z. Yajima, K. Shimizu and K. Morii ${ }^{1}$
}

\author{
AMS R \& D Center, Kanazawa Institute of Technology, 3-1 Yatsukaho, Matto, \\ Ishikawa 924-0838, Japan \\ ${ }^{1}$ Daido Steel Co., LTD, 2-30 Daido-machi, Minami-ku, Nagoya 457-0081, Japan
}

\begin{abstract}
Transformation characteristics, microstructures and tensile properties of a Ti-49.7at.\%Ni-1.38at.\%Co alloy have been investigated as a function of aging temperature and period. After a solution-treatment, the alloy was aged at $623 \mathrm{~K}$ and $723 \mathrm{~K}$ for $1.8,14.4,115.2$ and $230.4 \mathrm{ks}$ in argon atmosphere, followed by water cooling. Microstructures of the aged alloys were observed by using a transmission electron microscope operated at $200 \mathrm{kV}$. Fine $\mathrm{Ti}_{3} \mathrm{Ni}_{4}$ precipitates were observed in all the $623 \mathrm{~K}$ and $723 \mathrm{~K}$ aged alloys, and their size increased with increasing aging temperature and time. For the same aging time, the number of $\mathrm{Ti}_{3} \mathrm{Ni}_{4}$ precipitates per unit area for the $623 \mathrm{~K}$ aged alloy was larger than that for the $723 \mathrm{~K}$ aged alloy. The R-phase products were also observed in the aged alloys at $623 \mathrm{~K}$ and $723 \mathrm{~K}$ for 115.2 and $230.4 \mathrm{ks}$. Tensile properties of the aged alloys at $623 \mathrm{~K}$ and 723 $\mathrm{K}$ for $1.8 \mathrm{ks}$ were examined at temperatures higher than $\mathrm{A}_{\mathrm{f}}$ ' by $15 \mathrm{~K}$ with tensile speed of $8.3 \times 10^{-6} \mathrm{~m} / \mathrm{s}$. Critical stress for inducing B $19^{\prime}$ martensites, $\sigma_{\mathrm{M}}$, of the aged alloy at $723 \mathrm{~K}$ for $1.8 \mathrm{ks}$ was nearly equal to the aged alloy at $623 \mathrm{~K}$ for $1.8 \mathrm{ks}$, however, elongation at tensile fracture point of the former alloy was about 2 times longer than that of the latter one. These tensile properties were the same as those previously observed by the present authors, and they seemed to be interpreted by considering that the stress induced martensits were not developed in the aged alloy at $623 \mathrm{~K}$ for $1.8 \mathrm{ks}$ although they were done in the aged alloy at $723 \mathrm{~K}$ for $1.8 \mathrm{ks}$, because the number of $\mathrm{Ti}_{3} \mathrm{Ni}_{4}$ precipitates per unit area were larger in the former alloy than the latter alloy, as verified by TEM observation.
\end{abstract}

\section{Introduction}

Superelastic behavior of Ti-Ni-Co shape memory alloys is well known to be of a work-hardening type, not of a stress constant type as in binary $\mathrm{Ti}-\mathrm{Ni}$ shape memory alloys. In the previous papers reported by the present authors [1]-[3], tensile and fatigue properties of variously heat-treated Ti-Ni-Co alloys, which have different $R \rightarrow B 2$ transformation finish temperatures ( $A_{f^{\prime}}{ }^{\prime}$ ), were investigated at 295 $K$ and higher temperatures $\left(A_{f^{\prime}}+15 K\right)$. Critical stress for inducing $B 19$ ' martensites, $\sigma_{M}$, of the 723 $\mathrm{K}$ aged alloy was nearly equal to that of the $623 \mathrm{~K}$ aged alloy, however, elongation at tensile fracture point of the former alloy was about 2 times longer than that of the latter alloy. The present study was carried out to clarify the origin of the difference in elongation between the two aged alloys, in which transformation characteristics and microstructures of the two aged $\mathrm{Ti}-\mathrm{Ni}$-Co alloys were investigated as well as the tensile properties.

\section{Experimental Procedure}

The material investigated was prepared by high frequency vacuum induction melting, and its chemical composition was Ti-49.7at. $\% \mathrm{Ni}-1.38 \mathrm{at} \% \mathrm{Co}$. The ingot was cold rolled to the shape of plate with $5.0 \mathrm{~mm}$ width and $0.5 \mathrm{~mm}$ thickness. The plate-shaped specimens were solution-treated at $1223 \mathrm{~K}$ for $1.8 \mathrm{ks}$ in argon atmosphere followed by water quenching, and then they were aged at $623 \mathrm{~K}$ and $723 \mathrm{~K}$ for $1.8,14.4,115.2$ and $230.4 \mathrm{ks}$ in argon atmosphere followed by water cooling ( which are named 623-T alloy and 723-T alloy, $\mathrm{T}$ : aging time ).

Martensitic transformation behavior of the aged alloys was examined by a differential scanning calorimetry ( Shinku-Riko, MTS9000 ). TEM observations were carried out in a JEOL-2000FXII microscope operated at $200 \mathrm{kV}$. Specimens for TEM studies were mechanically polished, and then electro-polished by using a twin-jet type electro-polishing apparatus. 
Specimens for tensile tests were cut into ribbons having the shape of $L$ ( active gauge length ) $7.0 \mathrm{~mm}, w$ ( width ) $=3.5 \mathrm{~mm}$ and $t$ (thickness) $=0.5 \mathrm{~mm}$ from the above mentioned plates by using an electric discharge machine. The ribbon-shaped specimens were then lightly polished with alumina powder in order to remove a thin oxide surface layer. Tensile properties of 623-1.8 and 723-1.8 alloys were examined at temperatures of $\mathrm{A}_{\mathrm{f}}{ }^{\prime}+15 \mathrm{~K}$ by using a computer controlled material testing machine ( JT Toshi, SVF-200/25-CPU), the tensile speed being $8.3 \times 10^{-6} \mathrm{~m} / \mathrm{s}$.

\section{Results and Discussion}

\subsection{Transformation Behavior}

Figure 1 shows DSC curves taken of $623-1.8,-115.2,-230.4$ and $723-1.8,-115.2,-230.4$ alloys. Only one peak was clearly recorded on both the cooling and heating processes of the 623-T alloys, while two peaks were observed on both the cooling and heating processes of the 723-14.4, 115.2 and 230.4 alloys, i. e. B2 $\leftrightarrow \mathrm{R} \leftrightarrow \mathrm{B} 19$ '. For the 723-1.8 alloy, however, one peak of B2 $\rightarrow \mathrm{R}$ transformation and two peaks of $\mathrm{M} \rightarrow \mathrm{R} \rightarrow \mathrm{B} 2$ transformations were recorded on the cooling and heating processes, respectively. The one DSC peak in the 623-T alloy is considered to be caused by the B2 $\leftrightarrow R$ transformation, because the R-phase martensites were observed in TEM images taken of the 623-T alloys ( described in section 3.2 ). Aging effect on transformation temperatures of a Ti-Ni-Co alloy is identical to that of binary $\mathrm{Ti}-\mathrm{Ni}$ alloys [4]. That is, the transformation temperatures increased with increasing aging time. While for the same aging time, $M_{s}^{\prime}$ ( B2 $\rightarrow R$ transformation start temperature ) and $A_{f}{ }^{\prime}$ of the $723 \mathrm{~K}$ aged alloy were lower than those of the $623 \mathrm{~K}$ aged alloy.

\subsection{TEM Observation}

Figures 2 and 3 show typical TEM images and selected-area electron diffraction ( SAED ) patterns taken of $623 \mathrm{~K}$ and $723 \mathrm{~K}$ aged alloys. Fine lenticular precipitates were observed in both the
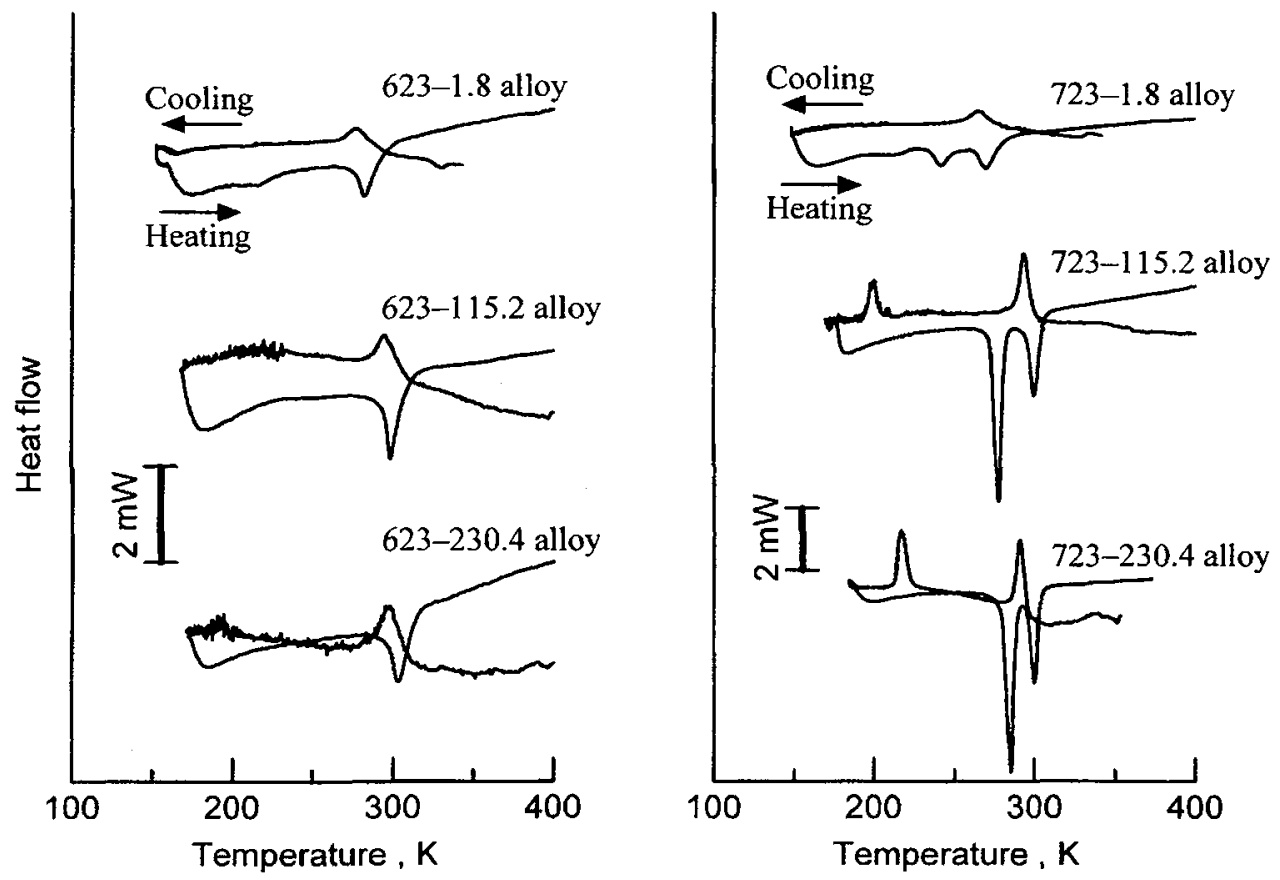

Figure 1 DSC curves of $623-1.8,-115.2,-230.4$ and $723-1.8,-115.2,-230.4$ aged alloys. 
aged alloys, and their size increased with increasing aging temperature and time. Dark contrasts surrounding the fine precipitates, which are caused by some strain field, were observed in both the aged alloy, especially for very fine precipitates. SAED pattern taken from a comparatively large precipitate ( encircled area in Figure 4 (a) ) in a 723-230.4 alloy is shown in Figure $4\left(a^{\prime}\right)$. In the SAED pattern, two kinds of reflections were observed with different intensities. Strong reflections, which are indexed with subscription $\mathrm{B} 2$, correspond to ones from B2 type lattice of the matrix. Other weak reflections align along the $\langle 321\rangle_{\mathrm{B} 2}$ reciprocal lattice vector, and are located at the positions dividing the length of the vectors into one-seventh. Similar electron diffraction patterns have been observed by $\mathrm{T}$. Tadaki et al. [5] in a binary $\mathrm{Ti}-\mathrm{Ni}$ alloy. According to their report, the weak reflections correspond to ones from the rhombohedral $\mathrm{Ti}_{3} \mathrm{Ni}_{4}$ precipitate. X-ray diffraction profiles consisting of $\mathrm{B} 2$ and $\mathrm{Ti}_{3} \mathrm{Ni}_{4}$ reflections were also obtained from 623-14.4, $-115.2,-230.4$ and $723-14.4,-115.2,-230.4$ alloys. Therefore, the lenticular precipitates observed in $623 \mathrm{~K}$ and $723 \mathrm{~K}$ aged Ti-Ni-Co alloys are concluded to be $\mathrm{Ti}_{3} \mathrm{Ni}_{4}$ precipitates, as observed in Ti-Ni binary alloys.

Typical TEM image and its SAED pattern of a R-phase product taken of a 723-230.4 alloy are shown in Figure 5. Similar R-phase products were observed in the 623-115.2, -230.4 and 723-115.2, alloys ( $A_{f}{ }^{\prime} \approx$ room temperature ). Hence, the one DSC peak observed for the 623-T alloy was attributed to the $B 2 \leftrightarrow R$ transformations.

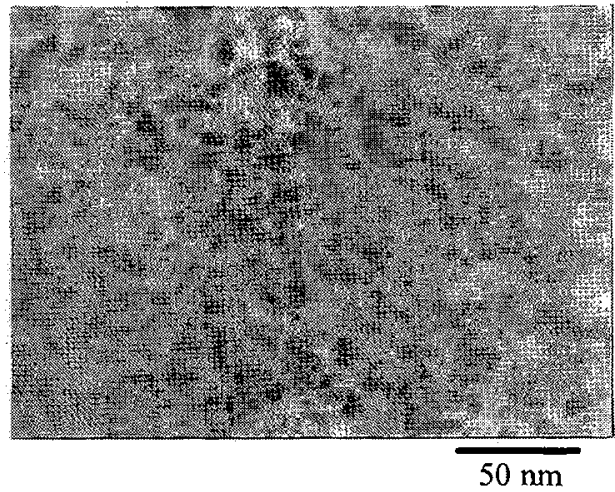

(a) 623-1.8 aged alloy

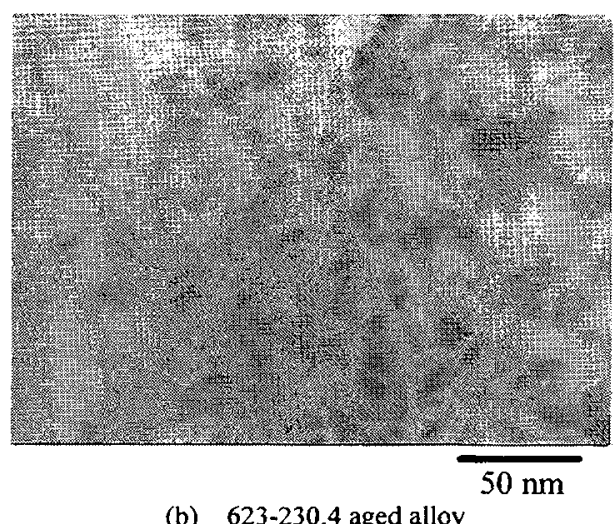

Figure 2 Bright field images taken of 623-1.8 and 623-230.4 aged alloys.

\subsection{Tensile Properties}

Stress - strain curves obtained for 623-1.8 and 723-1.8 alloys at temperatures of $\mathrm{A}_{\mathrm{f}}{ }^{\prime}+15 \mathrm{~K}$ are

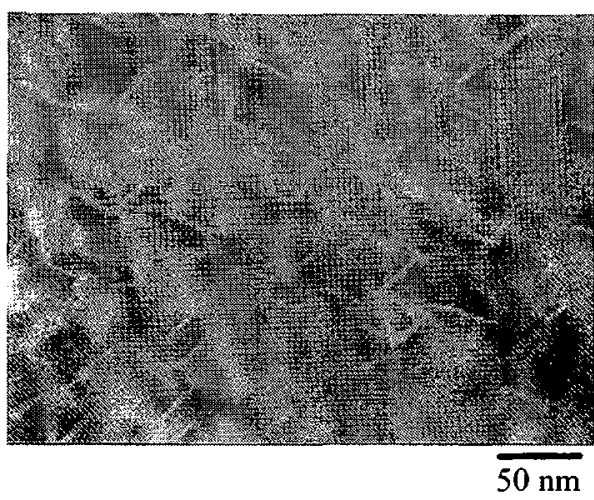

(a) Bright field image taken of 723-1.8 aged alloy
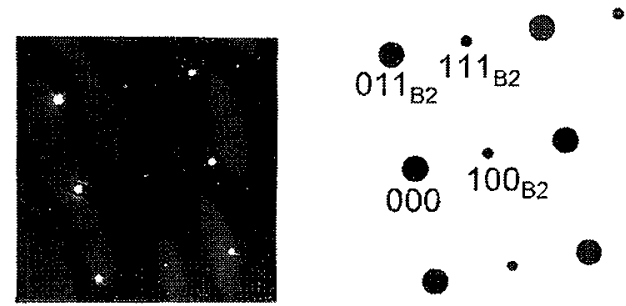

(a') SAED pattern taken of (a) and its key diagram.

Figure 3 Bright field image, SAED pattern and its key diagram taken of 723-1.8 aged alloy. 


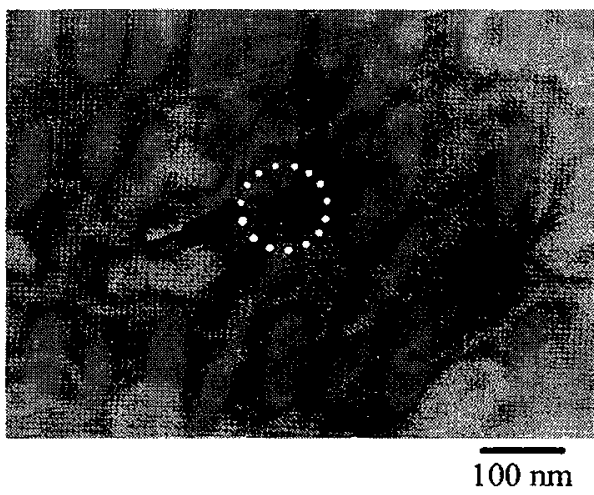

(a) Bright field image taken of 723-230.4 alloy.
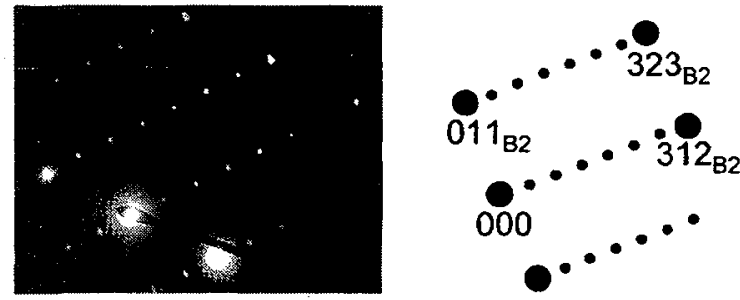

(a') SAED pattern taken of the encircled area in (a) and its key diagram.

Figure 4 TEM bright field image of comparatively large precipitates, SAED pattern and its key diagram taken of 723-230.4 aged alloy.

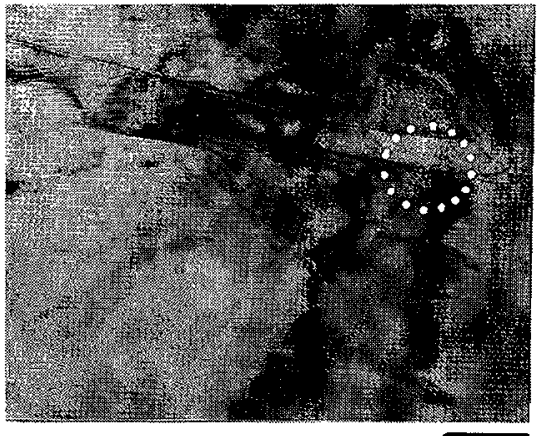

$200 \mathrm{~nm}$

(a) Bright field image taken of 723-230.4 alloy.
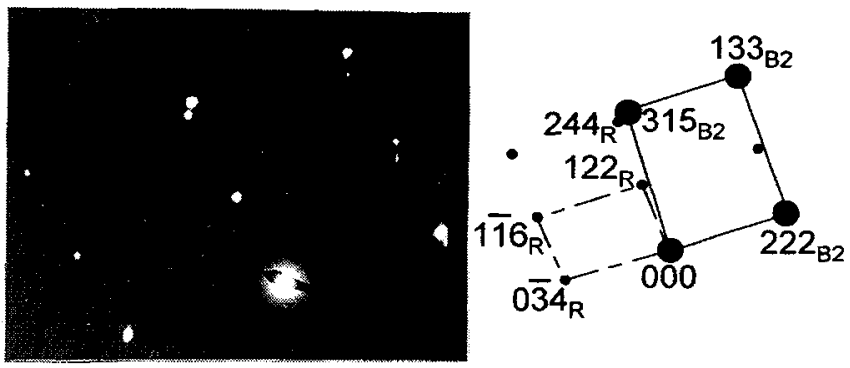

(a') SAED pattern taken of the encircled area in (a) and its key diagram.

Figure 5 Bright field image showing R-phase in 723-230.4 aged alloy and SAED pattern taken from the encircled area in the bright field image.

shown in Figure 6. An apparent plastic deformation is recorded after the liner elastic deformation on both the stress - strain curves. The apparent plastic deformation is due to the martensitic transformation, and critical stress for inducing B19' martensites, $\sigma_{M}$, was identified as the intersection of an extended line of the linear elastic region with that of the linear plastic region. The value of $\sigma_{M}$ for the 723-1.8 alloy was nearly equal to that for the 623-1.8 alloy, however, elongation at tensile fracture point for the 723-1.8 alloy was about 2 times longer than that for the 623-1.8 alloy. These results are the same as those previously reported by the present authors [1]-[3]. It is thought that this difference of stress - strain curve between the 623-1.8 and 723-1.8 alloys is due to some difference in distribution of $\mathrm{Ti}_{3} \mathrm{Ni}_{4}$ precipitates in both the alloys. According to the TEM observations, it has been found that the number of $\mathrm{Ti}_{3} \mathrm{Ni}_{4}$ precipitates per unit area for the 623-1.8 alloy is larger than that for the 723-1.8 alloy, that is, distance between precipitates is smaller in the former alloy than the latter. Therefore, it seems that the development of stress induced martensites in the 623-1.8 alloy is more difficult than that in the 723-1.8 alloy. As a result, stress - strain curves shown in Figure 6 are considered to be observed. 


\section{Conclusions}

Transformation characteristics, TEM microstructures and tensile properties of aged Ti-49.7at.\%Ni-1.38at.\%Co alloys have been investigated. Only one DSC peak was clearly recorded on both the cooling and heating processes of the 623-T alloys. According to the TEM observations, the one DSC peak was identified to be due to the $\mathrm{B} 2 \leftrightarrow \mathrm{R}$ transformation. Two DSC peaks were observed for the 723-14.4, 115.2 and 230.4 alloys, i. e. B2 $\leftrightarrow$ R $\leftrightarrow$ B19'. However, for the 723-1.8 alloy, one peak of $B 2 \rightarrow R$ transformation was recorded on the cooling process, but, two peaks of $\mathrm{M} \rightarrow \mathrm{R} \rightarrow \mathrm{B} 2$ transformations was on the heating processes. Aging effect on transformation temperatures of a Ti-Ni-Co alloy was thus identical to that of binary Ti-Ni alloys. Lenticular precipitates were observed in both the $623 \mathrm{~K}$ and $723 \mathrm{~K}$ aged alloys. These precipitates were identified to be $\mathrm{Ti}_{3} \mathrm{Ni}_{4}$ precipitates from TEM observation and X-ray diffraction analysis, and the inter-distance between $\mathrm{Ti}_{3} \mathrm{Ni}_{4}$ precipitates in the 623-1.8 alloy was smaller than that in the 723-1.8 alloy. Elongation at tensile fracture point for the latter alloy was about 2 times longer than that for the former alloy. Such a difference was also observed previously, and from the present TEM observation, the difference in elongation seems to be attributed to that stress induced martensites in the 623-1.8 alloy are hard to be developed compared to those in the 723-1.8 alloy.

\section{Acknowledgement}

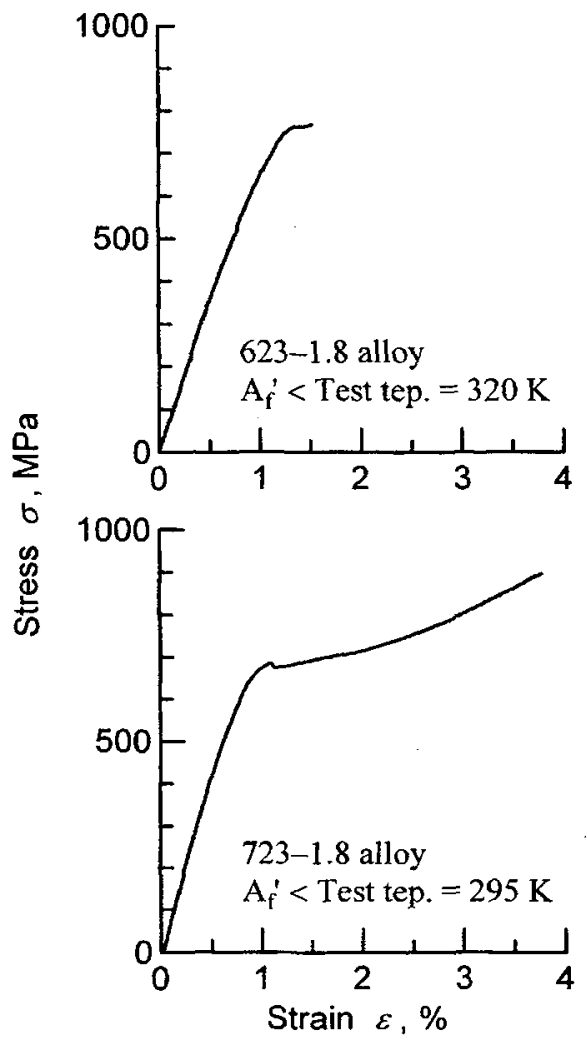

Figure 6 Stress - strain curves of 623-1.8 and 723-1.8 aged alloys tested at $A_{\mathrm{f}}{ }^{\prime}+15 \mathrm{~K}$.

This research was partially supported by Grant-in-Aid for Encouragement of Young Scientists (A), 11750577, and Scientific Research (C) 12650663 and 12650703 of the Ministry of Education, Science, Sports and Culture, Japan.

\section{References}

1. Y. Kishi, Z. Yajima and K. Shimizu, in Proceedings of China-Japan Bilateral Symposium on Shape Memory Alloys ( C-J SMA '97), Hangzhou, China, 1997, edited by C. Youyi and K. Otsuka ( International Academic Publishers, Beijing, P. R. China, 1998 ) pp. 75-80.

2. Y. Kishi, Z. Yajima, K. Shimizu and K. Morii, Materials Science and Engineering A, 273-275, pp. 654-657(1999).

3. Y. Kishi, Z. Yajima, K. Shimizu and K. Morii, Proceedings of the International Symposium and Exhibition on Shape Memory Materials (SMM'99), Kanazawa, Japan, 1999, edited by T. Saburi ( Trans Tech Publications, Switzerland, 2000 ), pp. 123-126.

4. T. Honma, in Keijou Kioku Gokin, edited by Y. Funakubo, ( Sangyo Tosho, Tokyo, Japan, 1985 ).

5. T. Tadaki, Y. Nakata, K. Shimizu and K. Otsuka, Transactions of the Japan Institute of Metals, 27, pp.731-740(1986). 